Ridmika, K.D.H., 2019. Constructing plastic roads using polymer-modified bitumen: A literature review. In: Sandanayake, Y.G., Gunatilake, S. and Waidyasekara, A. (eds). Proceedings of the $8^{\text {th }}$ World Construction Symposium, Colombo, Sri Lanka, 8-10 November 2019, pp. 210-219. DOI: doi.org/10.31705/WCS.2019.21. Available at: https://2019.ciobwcs.com/papers

\title{
CONSTRUCTING PLASTIC ROADS USING POLYMER-MODIFIED BITUMEN: A LITERATURE REVIEW
}

\author{
Kuragamage Dona Hiruni Ridmika ${ }^{1}$
}

\begin{abstract}
The flexible roads are the roads which are mainly constructed by using bitumen and asphalt. Flexible roads have problems due to their lack of durability, lack of strength etc. Therefore, this research was conducted to identify the possibility of using polymermodified bitumen as a solution for those problems. The research methodology used was literature review. Plastic waste can be used to prepare polymer-modified bitumen. The applicability, cons and pros; the environmental aspect and economical aspect of the polymer-modified bitumen were identified in this research. Moreover, polymer-modified bitumen is identified as a solution for the flexible roads' problems. Using the polymermodified bitumen in the road construction, addresses the problems of the flexible roads, by, increasing the roads' strength, avoiding breakage, facing the environmental conditions more effectively etc. Furthermore, it brings benefits such as the roads becoming more comfortable for the passengers. The most effective way of constructing the plastic roads is the dry process, over the wet process. Preparing the plastic roads is an environmentally friendly method, if only thermoplastics such as Low Density Polythene, High Density Polythene, Polyurethane and Polythene Terephthalate are used. So, the plastics which are recycled few times, Polyvinyl Chloride and thermosetting plastics usage needs to be avoided. This method is economical, because the bitumen content used in the road construction can be reduced and in long term, although the initial cost of implementing the method is high, the maintenance cost is reduced. Sri Lanka will be benefited, if this method is implemented in the construction industry.
\end{abstract}

Keywords: Plastic Waste; Polymer-Modified Bitumen; Road Construction; Sri Lanka.

\section{INTRODUCTION}

The resources used for the road construction vary due to the functions and the requirements of the roads (Hunter, 2000). Therefore, when selecting the materials for the road construction, considering its requirements are important. Mainly there are two types of pavements recognised as the flexible pavements and rigid pavements in the road construction (Mohod and Kadam, 2016). According to Mohod and Kadam (2016) bitumen and the asphalts are mostly used in the flexible pavements and whereas according to Chandra (2017) concrete is used in the rigid pavements, incorporated with subbase, base causes etc.

If the roads are high volume roads, the bitumen and concrete mixtures are used, whereas if the roads are low volume roads, normally simple unsurfaced compacted aggregates are used (Hunter, 2000). Therefore, flexible roads and the rigid pavements are mainly used for the high volume roads. Moreover, among those two, flexible road is the most

\footnotetext{
${ }^{1}$ Colombo School of Construction Technology, Sri Lanka, bluecaprox@gmail.com
} 
constructed type of road, although in flexible roads cracks and the ratting are often (Mohod and Kadam, 2016). Finding a solution for the flexible roads' shortcomings, can decrease the cost of the maintenance, which is important for the road construction industry. But a question arises on how to improve the flexible roads' condition and would that method be economical considering to the maintenance of the flexible roads so far.

Professor R. Vasudevan, who is an Indian chemistry professor, identified that the plastic waste can be coated on the aggregates, prior to mixing with the bitumen and then added to the bitumen mix in the road construction (Menon, 2016). Bitumen is a binding material, in the road construction field (Jamal, 2017). Shaikh et al. (2017) mentioned that plastic coating technique increases the roads' strength and durability. Therefore, it can be studied as to whether the plastic waste mixed with the bitumen of the flexible roads could increase the roads' quality and performance.

Anyhow, plastic is a non-biodegradable material, and causes pollution known as micro plastic pollution (Valavanidis, 2016). Moreover, plastic cannot be recycled many times (can be only recycled up to 3-4 times) and toxic gases can be released during melting of plastic (Menon, 2016). Therefore, prior to using plastic in the road construction, it is important to identify the consequences of using plastic in the road construction and how it affects the environment. As plastic waste is a worldwide problem, it is only viable to use waste plastic as a substance to enhance the roads' performance, if only this method is environmentally friendly. Identifying the economical aspect of this method is also important. This method will only be feasible to implement, if the benefits are higher, than the cost of implementing the process.

This research has been conducted through a literature review. The aim of the research was to identify whether using plastic waste to prepare the polymer-modified bitumen is an economical and an environment friendly method. Therefore, in order to achieve this aim, this research has achieved milestones such as, identifying the applicability of plastic waste in preparing the polymer-modified bitumen, its advantages and disadvantages, identifying the effect to the environment of using this method and the economical aspect of this method. Moreover, at the latter part of the research, possibility of implementing the polymer-modified bitumen method in Sri Lanka has been discussed.

\section{RESEARCH METHODOLOGY}

In order to achieve the research aim and objectives, this research has been carried out through a literature review.

\section{LITERATURE REVIEW}

\subsection{Applicability of Plastic Waste in Preparing the Polymer - MODIFIED BITUMEN}

Bitumen is made out of highly condensed polycyclic aromatic hydrocarbons (Prakash et al., 2014). As mentioned above, bitumen is used as a binding material in the road construction. The asphalt concrete used in the road construction consists of bitumen and aggregate (Kumar and Satyanarayana, 2015). Those materials are mainly used in the flexible roads as stated. In the road constructions, the bitumen can be modified and modified-bitumen can be prepared using the substances such as plastic, fly ash, crumb rubber (Singhal et al., 2016). 
The plastic consists of polymer along with the additives (Goodship, 2007). The polymer content can differ from 20\%-100\% depending on the requirement of plastic (Goodship, 2007). Therefore, the plastic is used to prepare the polymer-modified bitumen.

Figure 1 shows the mixes used in constructing the roads (CIPS, 2014). There are two types of mixtures used for road construction, known as hot mix and cold mix; and the plastics can be used as a binder or as a modifier under the hot mix (CIPS, 2014). Moreover, waste plastic can be used in other means such as modified processes, as additives etc., in the road construction process (CIPS, 2014).

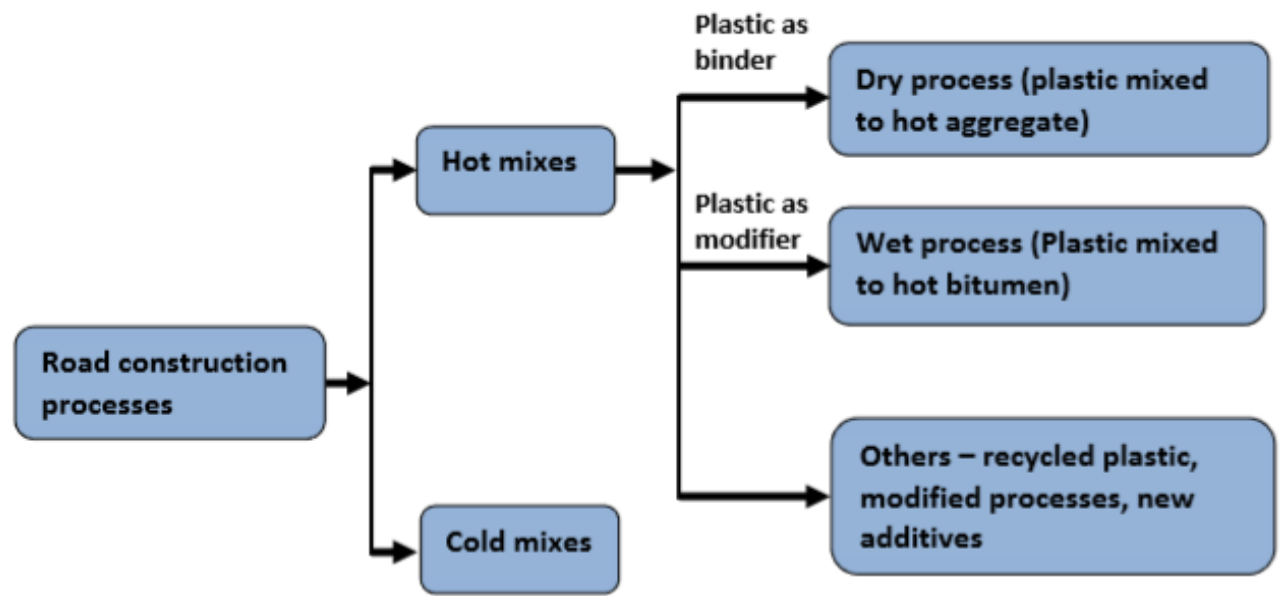

Figure 1: Mix types used in constructing roads (Source: Centre for Innovations in Public Systems [CIPS], 2014, p.36)

According to the Energy and Resources Institute (2017) plastic is only used in the hot mix because in order to prepare the polymer-modified bitumen, plastic is heated, therefore, only the hot mix is suitable. Therefore, the waste plastic can be used in the road construction process in different forms. But it's important to understand the most suitable process to use the waste plastic in the road construction process which brings more benefits to the society as well as which process is more environmental and economical friendly.

Figure 2 indicates dry process used in the road construction process (Yadav and Chandrakar, 2017). In the dry process, the plastic waste needs to be shredded and mixed with the hot aggregate, therefore, the waste plastic coated over the aggregate (Yadav and Chandrakar, 2017). In this process the waste plastic is used as a binder, which binds the mix (CIPS, 2014).

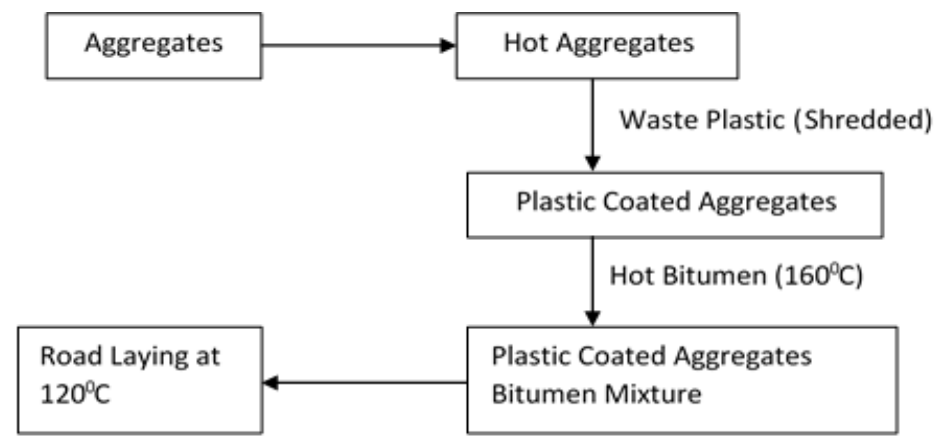

Figure 2: Dry process (Source: Yadav and Chandrakar, 2017, p.651) 
Figure 3 indicates the wet process used in the road construction process (Yadav and Chandrakar, 2017). In this process the plastic is heated and added to the bitumen mixture without coating it to the aggregate first (Yadav and Chandrakar, 2017). Therefore, the main difference between the wet process and the dry process is the method which the waste plastic is added to the mixture prior to get laid on the roads. Anyhow in both processes, heat is needed to add the waste plastic.

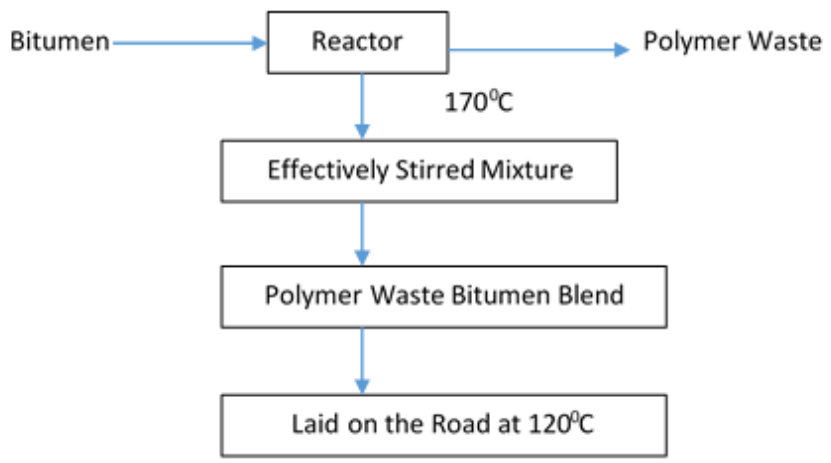

Figure 3: Wet process (Source: Yadav and Chandrakar, 2017, p.651)

Dry process can be used for plastic waste only, whereas wet process can be used for other materials such as rubber etc., as well (Gawande et al., 2012). But the wet process needs extra machineries and also other technologies, such as for cooling, to avoid air pockets (Gawande et al., 2012). Although the wet process can be used for other waste materials such as rubber, according to CIPS (2014), using the dry process makes the roads more durable and stronger. Yadav and Chandrakar (2017) stated that as in dry process the plastic is well coated on the aggregate, it increases the bonding between the substances in the mixture. Therefore, it can be understood that the reasons for the roads constructed using the dry process to have a higher strength and a durability is because the waste plastic increases the bonds between the materials, therefore, causes the roads to be strengthened.

According to the above discussion, it can be indicated that, although the wet process can be used for the waste materials such as rubber beside the plastic, the dry process is more effective if the plastic waste is used in preparing the bitumen, as it brings many benefits such as less cost due to lack of needs for special technology, higher strength, higher performance etc.

\subsection{COMPARISON ON ROAdS CONSTRUCTED USING POLYMER-MOdified BITUMEN AND REGULAR BITUMEN}

Prior to using the polymer-modified bitumen in the road construction field, it's important to understand the advantages of the polymer-modified bitumen compared to the regular roads. According to the CIPS (2014) using polymer-modified bitumen doubles the binding property of the bitumen mix, and also increases the roads' strength compared to normal roads. As bitumen is used as a binder in the road construction process, using plastic to the bituminous mixture is an advantage. Therefore, the materials in the mixture tend to have a higher bond, which will increase the strength of the road as well.

Kashiyani et al. (2013) stated that the roads' pores also decreased in the plastic roads up to $2 \%$. Moreover, using the modified bitumen affects the aggregates used in road construction in a beneficial way (Kashiyani et al., 2013). As the pores can be decreased in the roads by using polymer-modified bitumen, it reduces the bitumen oxidization 
which was the cause for the viscoelasticity and stops the bitumen from striping out from the aggregate (Kashiyani et al., 2013). Therefore, it can be understood that the plastic roads are more durable when compared to the normal flexible roads.

There is a limitation in the polymer-modified bitumen method, as due to the first rain, the plastic can be removed from the roads (Ali et al., 2018). But compared to the normal roads, polymer-modified bitumen roads can resist the rain and water logging due to less moisture absorbance (Kashiyani et al, 2013). So, plastic roads are beneficial, because although the first rain can affect the roads adversely, in long term it resists the adverse environmental condition effectively than the normal roads.

There can be potholes in the roads, where if the temperature of the environment increases up to $50^{\circ} \mathrm{C}$, or roads that are constructed in the sites which have extreme hot or humid conditions (Naathan and Chinnaraj, 2017). But plastic roads avoid potholes (CIPS, 2014). Moreover, Ultra-violet radiation causes aging of roads which grounds for cracking and stripping in the roads (Luo, 2017). If polymer-modified bitumen is used in the road construction, it stops the ultra-violet radiation (CIPS, 2014). Therefore, the cost of the plastic road maintenance tends to be lower in comparison to the flexible roads and the plastic roads tend to have a higher life span and lesser maintenance.

There is no threat of leaching the plastic out from the roads due to any chemical reactions (CIPS, 2014). Therefore, the society does not have to be concern about the chances of any harmful effect arising by the plastic roads, due to any chemical reactions. By using the Marshall Stability test, the maximum load that can be bore by a specimen can be identified (Rashid et al., 2018). CIPS (2014) mentioned that the Marshall Stability value is increased in the plastic roads. Therefore, the plastic roads can bear more load than the normal flexible roads and because of that the transportation service is benefited.

Marga (2005, cited by Sukartha et al., 2014) stated that the rebound deflection means the vertical pressure arises from a road when a motion happens. In the plastic roads the rebound deflection has also been reduced (Kashiyani et al., 2013). So, it makes easier for the passengers to travel in the plastic roads, as those roads are more comfortable to travel. Following Table 1 indicates the summary of the above comparison.

Table 1: Summary of the comparison

\begin{tabular}{|c|c|}
\hline Polymer-Modified Bitumen & Regular Bitumen \\
\hline $\begin{array}{l}\text { Binding ability has been doubled in } \\
\text { comparison to the regular bitumen }\end{array}$ & $\begin{array}{l}\text { Binding property is lower in comparison to } \\
\text { the polymer-modified bitumen }\end{array}$ \\
\hline $\begin{array}{l}\text { Less pores in the roads even in the extremely } \\
\text { hot/ humid environmental conditions }\end{array}$ & Comparatively, more pores on the roads \\
\hline $\begin{array}{l}\text { Reduce bitumen oxidization, which increases } \\
\text { the road quality }\end{array}$ & Comparatively high bitumen oxidization \\
\hline In the first rain, plastic can be washed away & No damages from the first rain \\
\hline $\begin{array}{l}\text { Comparatively, more resistant to adverse } \\
\text { weather conditions }\end{array}$ & $\begin{array}{l}\text { Comparatively, less resistant to the adverse } \\
\text { weather conditions }\end{array}$ \\
\hline No adverse chemical reactions & No adverse chemical reactions \\
\hline $\begin{array}{l}\text { The load which the road can bear is } \\
\text { comparatively high }\end{array}$ & $\begin{array}{l}\text { The load which the road can bear is } \\
\text { comparatively low }\end{array}$ \\
\hline
\end{tabular}




\begin{tabular}{ll}
\hline \multicolumn{1}{c}{ Polymer-Modified Bitumen } & \multicolumn{1}{c}{ Regular Bitumen } \\
\hline $\begin{array}{l}\text { Helps to prevent the road aging caused by the } \\
\text { ultra-violet radiation }\end{array}$ & $\begin{array}{l}\text { Tends to face road aging by ultra-violet } \\
\text { radiation }\end{array}$ \\
$\begin{array}{l}\text { Less rebound deflect makes the passengers } \\
\text { more comfortable }\end{array}$ & $\begin{array}{l}\text { High rebound deflect can makes to } \\
\text { passengers uncomfortable }\end{array}$ \\
\hline
\end{tabular}

According to the comparison, comparatively, by using polymer-modified bitumen, the performance of the flexible roads can be enhanced, compared to the normal flexible roads. Therefore, the strength, durability of the flexible roads increase, and the plastic roads addresses the problems in the normal flexible roads effectively.

\subsection{ECOLOGICAL ASPECTS OF USING MOdified BITUMEN}

The plastic waste has been an issue to the whole world. Plastics manufactured are mostly not recycled but dumped into the water, lands, etc (United Nations Environment, 2018). According to United Nations Environment (2018), only 9\% of the manufactured plastic is recycled. Therefore, prior to using plastic in the road constructions, it is important to know how the plastic roads affect the environment.

Plastic is divided into two categories for recycling, mainly considering the molecular structure (Goodship, 2007). They are thermosetting plastics and thermoplastics (Goodship, 2007). The plastic which can be remoulded are thermoplastics (Indian roads congress [IRC], 2013). Thermosetting plastic cannot be remoulded (Goodship, 2007).

CIPS (2014) emphasized that the temperature at which the polymer-modified bitumen is prepared similar to the temperature which the roads are constructed. According to Gawande et al. (2012) in the temperature of $155^{\circ} \mathrm{C}-165^{\circ} \mathrm{C}$ the bitumen is prepared. When preparing the polymer-modified bitumen, when using thermoplastic, between the temperatures of $130^{\circ} \mathrm{C}-180^{\circ} \mathrm{C}$, toxic gases are not released (Gawande et.al, 2012). Therefore, it's only safe to use thermoplastics to prepare the plastic roads.

So, to make the process of preparing the plastic roads safe, first, the plastic needs to be sorted out and only thermoplastic shall be used in the process. Moreover, this method is an environment friendly method because in the process of disposing, this method does not release Carbon Dioxide (CIPS, 2014). Gawande et al. (2012) and CIPS (2014) have also mentioned that this method as an eco-friendly method. It can be also mentioned as an eco-friendly way of thermoplastic recycling.

From the thermoplastics types, only LDPE, HOPE, Polyurethane and PET are the types relevant for constructing the plastic roads (IRC, 2013). Plastics that are recycled few times which become black in colour and PVC plastics tend to release toxic gases (CIPS, 2014). Therefore, those plastics cannot be used in this process. Moreover, the plastic which are mixed with toxins can be leached out from the plastic when cleaning; and also when the road is constructed if the chlorine had been mixed with the plastics that are used in the process, those chlorine can be released as HCL (Sabadra, 2017).

In order to make the plastic road preparation environment friendly, the plastic shall be sorted out and only the suitable plastics shall be used. And this method is a suitable method to recycle the thermoplastics. But the strict monitoring is important in order to make this a safely procedure and to prevent releasing toxic gases to the environment. 


\subsection{ECONOMIC ASPECTS OF USING MODIFIED BITUMEN}

The preparation of plastic roads needs to be an impetus method for the government in order to implement it in a country. Moreover, the benefits of the method need to be higher than the cost, for this method to be effective.

Plastic collection process required resources (Gawande, 2013) and also the preparing process of polymer-modifiers has a cleaning and a shredding process (Sutar et al., 2016). Because of that, more mechanical power and the human power is needed for constructing the plastic roads comparing to the normal flexible roads. But when considering about the monetary aspect, it is important to consider about the long term benefits of plastic road method. As mentioned by Gawande (2013), generally in the normal flexible roads the maintenance cost is high as the roads degrade fast, therefore, upgradation needs to be done (Gawande, 2013). But in plastic roads the maintenance cost is reduced.

Taking an example from India, a few states in India use the technology of plastic roads positively according to Mir (2015). Moreover, this method increases the lifespan of the roads up to ten years which was 4-5 years in the normal flexible roads (Trimbakwala, 2017). Furthermore, the maintenance of the roads is reduced, as the roads only need to be maintained once in ten years, when the polymer modified bitumen is used, which is for normal roads, the roads need to be maintained more frequently (CIPS, 2014). As stated, since the maximum load borne by the plastic roads are higher, the roads tend to resist heavy loads. Therefore, the cracks in the roads can be minimized, which will lead to less maintenance again.

Moreover, bitumen is an important material used in the road construction process. The plastic roads cut the bitumen usage of the roads by around $10 \%$ and also in one km length four meters width road, 1 ton of bitumen can be reduced by the usage of waste plastic (Kashiyani et al., 2013). Therefore, the amount of the bitumen used can be reduced with the plastic usage. This is a huge benefit as the contractors can buy waste plastic for lower prices when comparing to the bitumen. Further, there is an opportunity for the society from the plastic roads, as the public health workers get more jobs (CIPS, 2014). As such, since the preparation of polymer-modified bitumen needs more workforce for collecting plastics, sorting the plastic etc., it is a huge opportunity for the public health workers.

Accordingly, the implementation process of the polymer-modified bitumen method can be high as extra machinery and workforce is needed. But as the bitumen content used is minimized, thus the cost of the construction can be reduced. Moreover, comparatively the future maintenance cost is reduced and therefore, the government can save a huge amount of money from the maintenance since the lifespan of the roads is nearly doubled as well.

\subsection{POLYMER-MODIFIED BITUMEN CONSTRUCTION FOR SRI LANKA}

In Sri Lanka, the Asset group of companies has introduced using plastic waste in the road construction by introducing an asphalt mix, which contains plastic (The Island, 2018). But yet the technique of preparing the polymer-modified bitumen for the roads using the waste plastic, is not popular within the country. The asset group is planning to make the plastic road a milestone in the Sri Lankan construction industry (The Island, 2018).

According to Economynext (2018), the first plastic road constructed in Sri Lanka is from Ratmalana to Borupana. Economynext (2018) discussed that in this road waste plastic is coated in the aggregate before mixing with aggregate. Therefore, it can be identified that 
the dry method is used in the pilot project in Sri Lanka. But still this method is not recognized by many Sri Lankan professionals yet.

Christopher (2016) stated that in Sri Lanka averagely 5,163,689 kilos of plastic waste is produced per day. If the plastic waste is sorted out and if only the thermoplastics are used for the road construction, the Sri Lankan road construction industry can be benefited without causing any harm to the environment. But prior to implementing this method, relevant safety measures need to be identified in order to prevent releasing toxic gases. Furthermore, if the Sri Lankan government can introduce a framework for a plastic road it will be more significant to the industry. Although the monetary value to be spent for the government is high, considering the long term benefits and the environmental benefits, the government shall implement this method in order to enhance the performance and durability of the roads and also as beneficial method to recycle the relevant thermoplastics.

\section{CONCLUSIONS}

This research has concluded that the polymer-modified bitumen process is a successful method if it is implemented with the relevant standards, such as only suitable plastics shall be used, the suitable temperature shall be used etc. Considering the advantages of using polymer-modified bitumen method to the road construction industry, over the normal flexible roads, the polymer-modified bitumen roads have more advantages and it is also an environmentally friendly to implement and more economically effective.

With the development of a country, the roads' quality needs to be enhanced. Therefore, the core importance of applying the plastic road method to the construction industry, is that with a bearable cost the government could develop the road construction industry by recycling the thermoplastic waste. It can be recommended that this is a suitable method to be implemented in Sri Lanka. The Sri Lankan government and also the construction industry of Sri Lanka can be benefited if this method is implemented. Not only that, this method will be a huge advantage to the transportation industry as well. But Sri Lanka needs to overcome the barrier of poor waste management.

It can be recommended for the Sri Lankan government to use the usage of plastic waste effectively in the construction process as a tender evaluation criterion in the future. But the plastic roads method is not familiar in the Sri Lankan industry. So, the stakeholders of the construction industry, need to implement an installation about this topic by conducting continuous Professional Development programs, seminars etc. Consequently, this research area needs to be carried forward in Sri Lanka. As a future research area, the researchers can carry forward this research to identify the method to advance the plastic road construction method to incorporate all types of plastic waste in flexible road construction. Moreover, the possibility of using waste plastic in other construction aspects can also be identified as a relevant research area for future studies.

\section{REFERENCES}

Ali, I., Kumar, R., Mev, U.K., Jakhar, M., and Ali, I., 2018. Application of Plastic Waste Management in Road Construction. International Journal of Civil, Mechanical and Energy Science (IJCMES), 4(2), pp.22-25.

Centre for innovations in public systems (CIPS)., 2014. Use of plastics in road construction: Implementation of technology and roll out [online]. Available from 
https://www.aphrdi.ap.gov.in/documents/Trainings@APHRDI/2017/4_Apr/Muncipal\%20Waste\%20 Management/Kshitij\%20Aditeya.pdf [Accessed 15 February 2019]

Chandra, S., 2017. Flexible pavement versus rigid pavement [online]. Available from https://www.nbmcw.com/tech-articles/roads-and-pavements/36977-flexible-pavement-versus-rigidpavement.html [Accessed 22 September 2019]

Christopher, C., 2016. Sri Lanka among the 'dirty five'. The Sunday Times [online], 1 May 2016. Available from http://www.sundaytimes.lk/160501/news/sri-lanka-among-the-dirty-five-191570.html [Accessed 23 September 2019]

Economynext., 2018. Sri Lanka paves first road with plastic waste. Economynext [online], 3 October 2018. Available from https://economynext.com/sri-lanka-paves-first-road-with-plastic-waste-11730/ [Accessed 23 September 2019]

Gawande, A., Zamre, G.S., Renge, V.C., Bharsakale, G.R., and Tayde, S., 2012. Utilization of waste plastic in asphalting of roads. Scientific reviews and chemical communications, 2(2), pp.147-157.

Gawande, A.P., 2013. Economics and viability of plastic road: a review. Journal of current chemicals and pharmaceutical sciences, 3(4), pp.231- 242.

Goodship, V., 2007. Plastic recycling. Science Progress, 90(4), pp.245-268.

Hunter, R.N., 2000. Asphalts in road construction. London: Thomas Telford.

Indian Roads Congress (IRC)., 2013. Guidelines for the use of waste plastic in hot bituminous mixes (Dry process) in wearing courses [online]. New Delhi: Indian Road Congress. IRC: SP:98-2013 Available from https://www.tce.edu/sites/default/files/PDF/IRC-Spec=Road-with-plastic-waste.pdf [Accessed 21 February 2019]

Jamal, H., 2017. Types of bitumen and importance of bituminous materials [online]. Available from https://www.aboutcivil.org/importance-types-of-bituminous-materials.html [Accessed 21 February 2019]

Kashiyani, B., Pitroda, J., and Umrigar, F.S., 2013. Plastic waste: opportunities for eco-friendly material of bituminous road construction [online]. In Proceedings of National Conference, Vasad 20-21 December 2013. Available from: https://www.researchgate.net/publication/281272210_PLASTIC_WASTE_OPPORTUNITIES_FOR_ ECO-FRIENDLY_MATERIAL_OF_BITUMINOUS_ROAD_CONSTRŪCTION [Accessed 25 February 2019]

Kumar, U.A. and Satyanarayana, P.V.V., 2015. Comparison of the Polyethylene and SBS Polymer Modified Bitumen's Effect: A Case Study. International Journal of Engineering Trends and Technology (IJETT), 22(7), pp.325-330.

Luo, M., 2017. Study of asphalt performance impact with ultraviolet aging. IOP Conference Series: Materials Science and Engineering, Singapore 28-30 July 2017. IOP Pubishing. Available from https://www.researchgate.net/publication/319887049_Study_of_asphalt_performance_impact_with_u ltraviolet_aging [Accessed 21 February 2019]

Menon, A., 2016. Roads Made of Plastic Waste in India? Yes! Meet the Professor Who Pioneered the Technique [online]. Available from: https://www.thebetterindia.com/43685/plastic-waste-in-roadconstruction-plastic-man-india-prof-vasudevan/ [Accessed 17 January 2019]

Mir, A.H., 2015. Use of Plastic Waste in Pavement Construction: An Example of Creative Waste management. IOSR Journal of Engineering (IOSRJEN), 5(2), pp.57-67.

Mohod, M.V., and Kadam, K.N., 2016. A Comparative Study on Rigid and Flexible Pavement: A Review. IOSR Journal of Mechanical and Civil Engineering, 13(3), pp.84-88.

Naathan, S.B., and Chinnaraj, C., 2017. Effect of plastics and rubber in bitumen. South Asian Journal of Engineering and Technology, 3(7), pp.162-169.

Prakash, K.S., Phanindra, M., Surya, S.R., and Naresh, J., 2014. Percentage replacement of bitumen with sugarcane waste molasses. International Journal of Civil Engineering and Technology (IJCIET) [online], 5(7), pp.188- 197.

Rashid, G.M.H.O., Ahmed, B., Sobhan, M.A., and Rahman, N., 2018. Marshall Characteristics of Bituminous Mixes Using Reclaimed Asphalt Pavement. American Journal of Traffic and Transportation Engineering, 3(4), pp.57-61. 
Sabadra, V., 2017. Use of Polymer Modified Bitumen in Road Construction. International Research Journal of Engineering and Technology (IRJET), 4(12), pp.799-801.

Shaikh, A., Khan, N., Shah, F., Shukla, D., and Kale, G., 2017. Use of Plastic Waste in Road Construction. International journal of advance research and development, 2(5), pp.14-19.

Singhal, M., Yadav, Y., and Mandal, R., 2016. Use of Modified Bitumen in Highway Construction. International Journal for Innovative Research in Science and Technology, 2(12), pp.376-382.

Sukartha, M., Mochtar, I.B., and Santosa, W., 2014. Correlation of flexible pavement rebound deflection development trendline with its curve pattern after the road life cycle limit. International Journal of Education and Research, 2(7), pp.481-504.

Sutar, D.M., Patil, S., and Waghmare, A.P., 2016. Feasibility of Plastic Coat Road with respect to Cost and their performance. International Research Journal of Engineering and Technology (IRJET), 3(12), pp.1513-1518.

The Energy and Resources Institute., 2017. Life Cycle Assessment of Hot Mix and Cold Mix Technologies for Construction and Maintenance of Rural Roads [online]. Available from: http://www.teriin.org/eventdocs/files/Report_Rural-Roads.pdf [Accessed 1 March 2019]

The Island., 2018. Waste plastic for road surfacing?. The Island [online], 3 October 2018. Available from http://www.island.lk/index.php?page_cat=article-detailsandpage $=$ articledetailsandcode title $=192136$ [Accessed 12 February 2019]

Trimbakwala, A., 2017. Plastic Roads Use of Waste Plastic in Road Construction. International Journal of Scientific and Research Publications, 7(4), pp.137-139.

United Nations Environment., 2018. The state of plastics: World Environment Day Outlook 2018 [online]. Available

from https://wedocs.unep.org/bitstream/handle/20.500.11822/25513/state plastics WED.pdf?isAllowed=y \&sequence $=1$ [Accessed 20 February 2019]

Valavanidis, A., 2016. Global Plastic Waste and oceans' Pollution: Million tons of plastic waste have gone missing in the world oceans? [online]. Available from https://www.researchgate.net/publication/3019ZWRxs5wXgEwtXT6ixAMhK8zeuZNsCGGdceans'_P ollution_LeM254CsjJ3pzBgM4TkgbS48bY5oWKkqoK_Gone_Missing in the_World_Oceans [Accessed 2 February 2019]

Yadav, Y., and Chandrakar, R., 2017. Construction of plastic roads: An effective way to utilize wastes. International Research Journal of Engineering and Technology (IRJET), 4(11), pp.650-652. 